\title{
REQUIREMENTS AND INCENTIVES FOR REDUCING CONSTRUCTION VEHICLE EMISSIONS AND COMPARISON OF NONROAD DIESEL ENGINE EMISSIONS DATA SOURCES
}

\author{
Phil Lewis, P.E., S.M. ASCE \\ Graduate Research Assistant \\ Department of Civil, Construction, and Environmental Engineering \\ North Carolina State University \\ Raleigh, NC 27695-7908 \\ Telephone 919-269-6144 \\ Email mplewis@ncsu.edu \\ William Rasdorf, Ph.D., P.E., F. ASCE, Professor \\ Department of Civil, Construction, and Environmental Engineering \\ North Carolina State University \\ Raleigh, NC 27695-7908 \\ Telephone 919-515-7637, Fax 919-515-7908 \\ Email rasdorf@ncsu.edu \\ H. Christopher Frey, Ph.D., M. ASCE, Professor \\ Department of Civil, Construction, and Environmental Engineering \\ North Carolina State University \\ Raleigh, NC 27695-7908 \\ Telephone 919-515-1155, Fax 919-515-7908 \\ Email frey@ncsu.edu \\ Shih-Hao Pang \\ Graduate Research Assistant \\ Department of Civil, Construction, and Environmental Engineering \\ North Carolina State University \\ Raleigh, NC 27695-7908 \\ Telephone 919-523-5824 \\ Email spang@ncsu.edu \\ Kangwook Kim \\ Graduate Research Assistant \\ Department of Civil, Construction, and Environmental Engineering \\ North Carolina State University \\ Raleigh, NC 27695-7908 \\ Telephone 919-604-3677 \\ Email kkim2@ncsu.edu
}

Word Count: 7,435 +1 figure +6 Tables

(Title page, outline, $\&$ references not included)

Key Words: construction vehicles, construction equipment, diesel engines, air pollution, emissions, emissions regulations, NONROAD model, PEMS 


\title{
INCENTIVES AND REQUIREMENTS FOR REDUCING CONSTRUCTION VEHICLE EMISSIONS AND COMPARISON OF NONROAD DIESEL ENGINE EMISSIONS DATA SOURCES
}

\author{
Lewis, P., Rasdorf, W., Frey, C., Pang, S., Kim, K.
}

\author{
ABSTRACT \\ RELEVANCE TO THE CONSTRUCTION INDUSTRY \\ AIR POLLUTANT EMISSIONS OF NONROAD DIESEL ENGINES \\ EMISSIONS REGULATIONS \\ Technological Standards \\ Air Quality Standards \\ OTHER INCENTIVES FOR EMISSION REDUCTIONS \\ VEHICLES \\ SOURCES OF EMISSIONS DATA \\ EPA NONROAD Model \\ NONROAD Model Limitations \\ Nonroad Engine Population Estimates \\ Exhaust Emissions Estimates \\ Field Data Collection \\ Field Data Collection Limitations \\ Field Data Collection Instrumentation \\ Field Data Collection Environment \\ Vehicle Activity Modes \\ COMPARISONS OF EMISSIONS DATA \\ CONCLUSIONS AND RECOMMENDATIONS \\ FUTURE WORK \\ ACKNOWLEDGEMENTS \\ REFERENCES
}




\title{
INCENTIVES AND REQUIREMENTS FOR REDUCING CONSTRUCTION VEHICLE EMISSIONS AND COMPARISON OF NONROAD DIESEL ENGINE EMISSIONS DATA SOURCES
}

\author{
Lewis, P., Rasdorf, W., Frey, C., Pang, S., Kim, K.
}

\begin{abstract}
Nonroad construction vehicles and equipment powered by diesel engines contribute to mobile source air pollution. The engines of this equipment emit significant amounts of carbon monoxide, hydrocarbons, nitrogen oxides, and particulate matter. These pollutants pose serious problems for human health and the environment. Therefore, it is necessary to regulate and control the levels of these pollutants. Furthermore, there are emerging requirements and incentives for "greening" of construction vehicle fleets and operations. Currently, there are two types of standards that regulate air pollution for these types of vehicles: technological standards for engines and quality standards for air.
\end{abstract}

It is also necessary to quantify the levels of emissions that nonroad construction vehicles and equipment produce. Quantification may be based on existing data sources (such as the EPA NONROAD model) or by collecting data directly from the vehicles as they work in the field. The purpose of this paper is to introduce the challenges to quantification of emissions from nonroad construction vehicles, describe associated governmental regulations and incentives for reducing emissions, identify and compare various sources of emissions data, establish the need to collect additional data, and propose a future research agenda that focuses on air pollution generated by construction vehicles.

\section{RELEVANCE TO THE CONSTRUCTION INDUSTRY}

All fuel-powered vehicles contribute to air pollutant emissions. Construction vehicles and equipment are no exception. Construction vehicles are typically powered by diesel engines and are considered to be a nonroad source of air pollution. Such vehicles are typically transported between sites on a highway via a trailer.

Air pollution refers to the presence of undesirable materials in the air that exist in quantities large enough to produce harmful effects [Seinfeld and Pandis, 1998]. These undesirable materials may cause damage to human health, vegetation, property, or to the environment. In addition, air pollution may create brown, hazy air and unpleasant odors [Cooper and Alley, 2002].

The United States Environmental Protection Agency (EPA) estimates that there are approximately two million items of construction equipment in the United States. Nonroad diesel engines, such as those found in construction vehicles and equipment, are significant sources of air pollution. For example, a bulldozer with a 175 horsepower engine emits as much particulate matter as 500 new automobiles [EPA, 2005a]. Therefore, it is imperative to reduce pollution from this source to provide a healthier environment for construction employees and the public and to reduce overall environmental impact. By reducing pollution, equipment owners are also able to save fuel and money.

Further reductions in emissions by the construction industry are certain as a result of regulatory and incentive programs. A necessary first step to achieving reductions is to accurately 
benchmark and quantify real-world emissions. Further, changes in industry behavior and attitude and changes in vehicle and equipment operation and control will likely be needed. The purpose of this paper is to:

- Introduce the nonroad construction vehicle air pollutant emissions problem.

- Describe the governmental regulations that limit air pollutant emissions.

- Identify various sources of construction vehicle emissions data.

- Compare the construction vehicle emissions data from various sources.

- Establish the need to collect and analyze new data.

- Map and prioritize a future research agenda related to the collection, analysis, and use of construction vehicle emissions data.

With additional technological standards expected in the future, the construction industry is well served to anticipate changes and contribute leadership in developing methods and searching for innovative ways to reduce air pollutant emissions. The industry has an obligation, which is becoming increasingly recognized, to initiate efforts to lower construction vehicle emissions. This paper begins to address this problem by suggesting an approach to first quantifying the magnitude of the problem.

\section{AIR POLLUTANT EMISSIONS OF NONROAD DIESEL ENGINES}

Air pollutant emissions from vehicles powered by diesel engines include nitrogen oxides $\left(\mathrm{NO}_{\mathrm{x}}\right)$, particulate matter (PM), hydrocarbons $(\mathrm{HC})$, and carbon monoxide $(\mathrm{CO})$. Any engine that combusts a nonrenewable carbonaceous fuel will have net emissions of carbon dioxide $\left(\mathrm{CO}_{2}\right)$. Although there are small amounts of sulfur in diesel fuel, diesel engines are not a significant source of sulfur dioxide $\left(\mathrm{SO}_{2}\right)$ emissions compared to coal-fired power plants. $\mathrm{NO}_{\mathrm{x}}$ and $\mathrm{PM}$ are of particular interest because they are emitted at relatively high rates per unit of fuel consumed, compared to other emission sources such as gasoline engines. However, $\mathrm{CO}$ and $\mathrm{HC}$ emissions from diesel engines are much lower per unit of fuel consumed than for gasoline engines.

Nitrogen oxides are formed by the combustion of fuel in air and contribute to the formation of smog and acid deposition. $\mathrm{NO}_{\mathrm{x}}$ may cause damage to plants and animals and ultimately affects human health. $\mathrm{NO}_{\mathrm{x}}$ reacts with volatile organic compounds (VOC) in the presence of sunlight to form photochemical oxidants, including ozone $\left(\mathrm{O}_{3}\right)$. Ozone is a severe eye, nose, and throat irritant and long-term exposure may cause irreversible, accelerated lung aging. Ozone also causes plant damage that result in crop and forest losses. Furthermore, ozone can cause deterioration of textiles, paints, rubber, and other materials [Seinfeld and Pandis, 1998].

Particulate matter is very small diameter solids or liquids that are discharged into the atmosphere, or are formed in the atmosphere as a result of emissions of precursors (including $\mathrm{NO}_{\mathrm{x}}$ ). Combustion processes are known to discharge these particles. PM contributes to the formation of smog and haze, reduces visibility, soils buildings and materials, and causes corrosion and erosion of materials. Furthermore, studies have attributed the following health problems to exposure to particulate pollution [EPA, 2008a]:

- Difficulty with breathing

- Coughing

- Irritation of the airways

- Reduced lung function 
- Aggravated asthma

- Chronic bronchitis

- Irregular heartbeat

- Nonfatal heart attacks

- Premature death in people with heart or lung disease

Carbon monoxide is a colorless, odorless, and tasteless gas that is caused by incomplete combustion of any fuel that contains carbon. The major source of $\mathrm{CO}$ in the atmosphere is combustion engines. Gasoline engines contribute a larger proportion of national $\mathrm{CO}$ emissions than diesel engines. This is because gasoline engines operate with approximately a stoichiometric air-to-fuel ratio, whereas diesel engines operate with excess air. The excess air improves the conversion of carbon in the fuel to $\mathrm{CO}_{2}$. Incompletely combusted carbon is typically emitted primarily in the form of $\mathrm{CO}$ as well as in the form of other products of incomplete combustion, which can include hydrocarbons.

Carbon monoxide has significant detrimental effects on human health. It reacts with the hemoglobin in human blood to prevent the transfer of oxygen. It may cause cardiovascular effects, such as chest pain, in those who suffer from heart disease. High levels of CO can affect healthy people by causing vision problems, reducing the ability to work or learn, reducing manual dexterity, and causing difficulty in performing complex tasks. In extremely high levels, $\mathrm{CO}$ is poisonous and can cause death [EPA, 2008a].

Hydrocarbons include volatile organic compounds that react with $\mathrm{NO}_{\mathrm{x}}$ in the presence of sunlight to form ground-level ozone. Many hydrocarbons are considered to be toxic, carcinogenic, or both, meaning that they may cause either short-term or long-term health effects ranging from temporary health effects to cancer. Hydrocarbon emissions are the result of incomplete combustion of fuel and also fuel evaporation [Cooper and Alley, 2002].

\section{EMISSIONS REGULATIONS}

The primary incentive for reducing construction vehicle emissions is government regulation mandating such reductions. There are two primary types of regulations aimed at reducing the level of air pollutant emissions from nonroad diesel engines. The purpose of one type is to establish technological standards that impose restrictions on the diesel engines themselves. The purpose of the other type is to establish air quality standards that limit the acceptable level of air pollutant emissions in the atmosphere. This section describes federal standards with respect to both types of regulation.

\section{Technological Standards}

In May 2004, EPA completed a comprehensive final rule as part of its Clean Diesel Program [EPA, 2007a]. The purpose is to reduce emissions from nonroad diesel engines, such as those found in locomotives, ships, and vehicles and equipment used for agriculture and construction. These requirements will be completely phased in by the year 2014. These new standards are expected to reduce emissions from nonroad diesel engines, particularly $\mathrm{NO}_{\mathrm{x}}$ and $\mathrm{PM}$, by $90 \%$ from the levels prior to the implementation of the final rule. 
These reductions are to take place by integrating fuel specifications, engine modifications, and post-combustion controls. New fuel requirements imposed on diesel fuel manufacturers will reduce the allowable levels of sulfur in fuel used by nonroad diesel engines by $99 \%$ from the levels prior to the implementation of the final rule. The restrictions on sulfur content in nonroad diesel fuel are intended to enable the use of post-combustion emission controls for other pollutants (such as diesel particulate traps for PM and selective catalytic reduction for $\mathrm{NO}_{\mathrm{x}}$ ) in order to meet requirements in future years. These post-combustion controls are sensitive to sulfur levels in the exhaust. Sulfur can lead to deactivation of catalysts and other types of degradation. Because nonroad diesel engines are not a significant source of $\mathrm{SO}_{2}$ emissions, the reduction in fuel sulfur content is less significant with respect to such emissions.

Regulations of pollutant emissions have been evolving in recent years. In 1994, the EPA adopted the first set of emission standards, known as Tier 1, for all new nonroad diesel engines greater than 50 horsepower. Any such engine manufactured after a specified date must meet the performance levels specified in the standard. The Tier 1 standards mandated $\mathrm{NO}_{\mathrm{x}}$ emissions reductions of $30 \%$, based on a standardized certification test, not real-world conditions. The Tier 1 standards were phased in for different engine sizes between 1996 and 2000 [EPA, 2007b].

In 1998, EPA adopted more stringent standards, known as Tier 2 and Tier 3, for $\mathrm{NO}_{\mathrm{x}}$, $\mathrm{HC}$, and PM for new nonroad diesel engines. This program included standards for engines less than 50 horsepower. Tier 2 phased in stricter requirements for engines manufactured from 2001 to 2006 depending on engine size, and Tier 3 phased in more stringent requirements for engines in the range of 50 to 750 horsepower manufactured from 2006 to 2008. The most stringent regulations will be implemented in two phases: Tier 4 Transitional standards beginning in 2011 and Tier 4 Final standards beginning in 2013 [EPA, 2007b].

Table 1 summarizes the EPA engine tier classifications and emission standards for engine power level ranges commonly found in nonroad construction vehicles and equipment. Note that there were no emissions standards prior to the implementation of Tier 1 standards for each category. Although not shown in Table 1, there are emission standards for generators with engines larger than 750 horsepower. However, such large generators are not typically used in construction activities.

The engine tier classifications are based on the engine horsepower and engine model year. Additionally, the emission standards for each engine tier are given for $\mathrm{HC}, \mathrm{NMHC}+\mathrm{NO}_{\mathrm{x}}$ (the combined emissions of non-methane hydrocarbons and nitrogen oxides), $\mathrm{CO}, \mathrm{NO}_{\mathrm{x}}$, and $\mathrm{PM}$ in units of grams per horsepower-hour. For example, as shown in Table 1, a 90 horsepower diesel engine will have a Tier 4 Final emission standard for $\mathrm{NO}_{\mathrm{x}}$ of 0.30 grams per horsepower-hour as opposed to a Tier 1 emission standard for $\mathrm{NO}_{\mathrm{x}}$ of 6.9 grams per horsepower-hour. This is a reduction of $95.7 \%$ [EPA, 2004a].

The Tier 4 Final rule will affect more than 650,000 items of nonroad diesel equipment that are sold in the United States each year [EPA, 2005b]. There are currently about six million items of nonroad diesel equipment, including construction equipment, in use in the United States. Based on the average expected equipment lifetime, the entire inventory of equipment is expected to be replaced by the year 2030 with most equipment meeting the Tier 4 Final requirements by then. 
When the entire inventory of older nonroad engines has been replaced with engines that meet the Tier 4 Final requirements, the EPA estimates that national nonroad $\mathrm{NO}_{\mathrm{x}}$ will be reduced by approximately 738,000 tons per year and PM will be reduced by approximately 129,000 tons per year. Furthermore, the EPA expects to annually prevent:

- 6,000 children's asthma-related emergency room visits

- 8,900 hospitalizations

- 12,000 premature deaths

- 15,000 non-fatal heart attacks

- 280,000 cases of respiratory symptoms in children

- 1,000,000 lost work days

These estimates are based on all nonroad diesel engines, not only those associated with construction vehicles and equipment. However, it is clear that these regulations will provide dramatic environmental and health benefits [EPA, 2005b].

Implementing the technological standards is the responsibility of diesel engine manufacturers; however, field practices of construction vehicle operators can be adjusted to reduce emissions, such as reducing or limiting engine idle time.

\section{Air Quality Standards}

The Clean Air Act (CAA) of 1970 required the EPA to establish National Ambient Air Quality Standards (NAAQS) for ambient concentrations of pollutants that are considered to be harmful to human health and the environment. The NAAQS are reviewed and, if appropriate, revised periodically. There are two types of national air quality standards. Primary standards provide limits to guard public health, including sensitive people such as asthmatics, children, and the elderly. Secondary standards provide limits to protect public welfare, such as the prevention of reduced visibility and the prevention of damage to buildings, animals, crops, and vegetation [CFR, 2007].

The EPA has established NAAQS for six principal pollutants, known as criteria pollutants. These criteria pollutants and the current NAAQS for each are shown in Table 2. Of these, CO, $\mathrm{NO}_{2}, \mathrm{SO}_{2}$, ozone $\left(\mathrm{O}_{3}\right)$, and $\mathrm{PM}$ are related to nonroad diesel engine emissions; only lead is not [CFR, 2007]. Here, we quantify emissions of $\mathrm{HC}, \mathrm{CO}, \mathrm{NO}_{\mathrm{x}}$, and $\mathrm{PM}$ for construction vehicles. Although $\mathrm{HC}$ is not a criteria pollutant, it is a precursor to $\mathrm{O}_{3}$, which itself is a criteria pollutant.

The units for the standards shown in Table 2 are reported as concentrations, either mass of pollutant $(\mathrm{mg}$ or $\mu \mathrm{g})$ per unit of volume $\left(\mathrm{m}^{3}\right)$ or parts per million $(\mathrm{ppm})$. These concentrations are based on hourly, quarterly, or annual averaging times. For example, the primary standard for $\mathrm{NO}_{2}$ is $100 \mu \mathrm{g} / \mathrm{m}^{3}$ based on the annual arithmetic mean. The secondary standard for $\mathrm{NO}_{2}$ is the same as the primary standard. 
Table 1. EPA Engine Tier Classifications [EPA, 2004a]

\begin{tabular}{|c|c|c|c|c|c|c|c|}
\hline \multirow{2}{*}{$\begin{array}{c}\text { Engine } \\
\text { Horsepower } \\
\text { (HP) }\end{array}$} & \multirow[b]{2}{*}{ Model Years } & \multirow[b]{2}{*}{ Regulation } & \multicolumn{5}{|c|}{ Emission Standards (g/hp-hr) } \\
\hline & & & $\mathbf{H C}^{\mathbf{a}}$ & $\begin{array}{c}\text { NMHC } \\
+\mathrm{NO}_{x}\end{array}$ & CO & $\mathbf{N O}_{\mathbf{x}}$ & $\mathbf{P M}$ \\
\hline \multirow{5}{*}{$50 \leq \mathrm{HP}<75$} & $1998-2003$ & Tier 1 & NS & $\mathrm{NS}$ & NS & 6.9 & NS \\
\hline & $2004-2007$ & Tier 2 & NS & 5.6 & 3.7 & NS & 0.30 \\
\hline & $2008-2012$ & Tier 3 & NS & 3.5 & 3.7 & NS & 0.22 \\
\hline & $2008-2012$ & Tier 4 Transitional $^{b}$ & NS & 3.5 & 3.7 & NS & 0.22 \\
\hline & $2013+$ & Tier 4 Final $^{\mathrm{b}}$ & NS & 3.5 & 3.7 & NS & 0.02 \\
\hline \multirow{5}{*}{$75 \leq \mathrm{HP}<100$} & $1998-2003$ & Tier 1 & NS & NS & NS & 6.9 & NS \\
\hline & $2004-2007$ & Tier 2 & NS & 5.6 & 3.7 & NS & 0.30 \\
\hline & $2008-2011$ & Tier 3 & NS & 3.5 & 3.7 & NS & 0.30 \\
\hline & $2012-2013$ & Tier 4 Transitional ${ }^{\mathrm{c}}$ & $0.14(50 \%)$ & NS & 3.7 & $0.30(50 \%)$ & 0.01 \\
\hline & $2014+$ & Tier 4 Final & 0.14 & NS & 3.7 & 0.30 & 0.01 \\
\hline \multirow{5}{*}{$100 \leq \mathrm{HP}<175$} & $1997-2002$ & Tier 1 & NS & NS & NS & 6.9 & NS \\
\hline & $2003-2006$ & Tier 2 & NS & 4.9 & 3.7 & NS & 0.22 \\
\hline & $2007-2011$ & Tier 3 & NS & 3.0 & 3.7 & NS & 0.22 \\
\hline & $2012-2013$ & 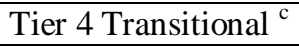 & $0.14(50 \%)$ & NS & 3.7 & $0.30(50 \%)$ & 0.01 \\
\hline & $2014+$ & Tier 4 Final & 0.14 & NS & 3.7 & 0.30 & 0.01 \\
\hline \multirow{5}{*}{$175 \leq \mathrm{HP}<300$} & $1996-2002$ & Tier 1 & 1.0 & NS & 8.5 & 6.9 & 0.40 \\
\hline & $2003-2005$ & Tier 2 & NS & 4.9 & 2.6 & NS & 0.15 \\
\hline & $2006-2010$ & Tier 3 & NS & 3.0 & 2.6 & NS & 0.15 \\
\hline & $2011-2013$ & 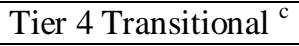 & $0.14(50 \%)$ & NS & 2.6 & $0.30(50 \%)$ & 0.01 \\
\hline & $2014+$ & Tier 4 Final & 0.14 & NS & 2.6 & 0.30 & 0.01 \\
\hline \multirow{5}{*}{$300 \leq \mathrm{HP}<600$} & $1996-2000$ & Tier 1 & 1.0 & NS & 8.5 & 6.9 & 0.40 \\
\hline & $2001-2005$ & Tier 2 & NS & 4.8 & 2.6 & NS & 0.15 \\
\hline & $2006-2010$ & Tier 3 & NS & 3.0 & 2.6 & NS & 0.15 \\
\hline & $2011-2013$ & 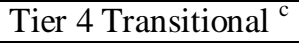 & $0.14(50 \%)$ & NS & 2.6 & $0.30(50 \%)$ & 0.01 \\
\hline & $2014+$ & Tier 4 Final & 0.14 & NS & 2.6 & 0.30 & 0.01 \\
\hline \multirow{5}{*}{$600 \leq \mathrm{HP}<750$} & $1996-2001$ & Tier 1 & 1.0 & NS & 8.5 & 6.9 & 0.40 \\
\hline & $2002-2005$ & Tier 2 & NS & 4.8 & 2.6 & NS & 0.15 \\
\hline & $2006-2010$ & Tier 3 & NS & 3.0 & 2.6 & NS & 0.15 \\
\hline & $2011-2013$ & Tier 4 Transitional $^{c}$ & $0.14(50 \%)$ & NS & 2.6 & $0.30(50 \%)$ & 0.01 \\
\hline & $2014+$ & Tier 4 Final & 0.14 & NS & 2.6 & 0.30 & 0.01 \\
\hline \multirow{4}{*}{$\begin{array}{c}750 \leq \mathrm{HP} \\
(\text { except } \\
\text { generators })\end{array}$} & $2000-2005$ & Tier 1 & 1.0 & NS & 8.5 & 6.9 & 0.40 \\
\hline & $2006-2010$ & Tier 2 & NS & 4.8 & 2.6 & NS & 0.15 \\
\hline & $2011-2014$ & Tier 4 Transitional & 0.30 & NS & 2.6 & 2.6 & 0.075 \\
\hline & $2015+$ & Tier 4 Final & 0.14 & NS & 2.6 & 2.6 & 0.03 \\
\hline
\end{tabular}

NS $=$ No Standard

${ }^{\text {a }}$ Tier 4 standards are in the form of non-methane hydrocarbons (NMHC).

${ }^{\mathrm{b}}$ The Tier $3 \mathrm{NO}_{\mathrm{x}}$ standard of $3.5 \mathrm{~g} / \mathrm{hp}-\mathrm{hr}$ was implemented beginning in 2008. The Tier 4 Transitional standard also begins in 2008 , leaving the Tier $3 \mathrm{NO}_{x}$ standard unchanged but adding a $0.22 \mathrm{~g} / \mathrm{hp}-\mathrm{hr}$ PM standard.

${ }^{\mathrm{c}}$ Percentages are model year sales fractions required to comply with the indicated NOx and NMHC standards for model years where less than $100 \%$ is required. 
Although EPA is responsible for determining NAAQS, ensuring that the standards are met is typically the responsibility of individual states. States seek authority to administer these standards via a state implementation plan (SIP) that must be approved by the EPA. The SIP specifies the local procedures and timetables for meeting the NAAQS. Areas that do not meet the original deadlines for abatement are designated as nonattainment areas. In addition to the federal NAAQS, states can implement their own more stringent statewide ambient air quality standards.

Table 2. National Ambient Air Quality Standards [CFR, 2007]

\begin{tabular}{|c|c|c|c|}
\hline Pollutant & Primary Standard & Averaging Time & "Secondary Standard \\
\hline Carbon Monoxide (CO) & $\begin{array}{l}10 \mathrm{mg} / \mathrm{m}^{3} \\
40 \mathrm{mg} / \mathrm{m}^{3}\end{array}$ & $\begin{array}{l}\text { 8-hour } \\
\text { 1-hour }\end{array}$ & None \\
\hline Lead & $1.5 \mu \mathrm{g} / \mathrm{m}^{3}$ & Quarterly Average & Same as Primary \\
\hline Nitrogen Dioxide $\left(\mathrm{NO}_{2}\right)$ & $100 \mu \mathrm{g} / \mathrm{m}^{3}$ & Annual Arithmetic Mean & Same as Primary \\
\hline Particulate Matter $\left(\mathbf{P M}_{10}\right)$ & $150 \mu \mathrm{g} / \mathrm{m}^{3}$ & 24-hour & Same as Primary \\
\hline Particulate Matter $\left(\mathbf{P M}_{2.5}\right)$ & $\begin{array}{c}15.0 \mu \mathrm{g} / \mathrm{m}^{3} \\
35 \mu \mathrm{g} / \mathrm{m}^{3}\end{array}$ & $\begin{array}{c}\text { Annual Arithmetic Mean } \\
\text { 24-hour }\end{array}$ & Same as Primary \\
\hline Ozone $\left(\mathrm{O}_{3}\right)$ & $0.08 \mathrm{ppm}$ & 8-hour & Same as Primary \\
\hline Sulfur Dioxide $\left(\mathrm{SO}_{2}\right)$ & $\begin{array}{l}0.03 \mathrm{ppm} \\
0.14 \mathrm{ppm}\end{array}$ & $\begin{array}{c}\text { Annual Arithmetic Mean } \\
\text { 24-hour } \\
\text { 3-hour } \\
\end{array}$ & $0.50 \mathrm{ppm}$ \\
\hline
\end{tabular}

When an area receives nonattainment status, it is placed into one of seven categories of nonattainment: basic, marginal, moderate, serious, two severe categories, and extreme. There are specific criteria for compliance for each category. In general, more stringent requirements are placed on areas with the more severe categories of nonattainment [Tietenberg, 2007].

As of March 2008, the EPA had determined that 337 counties nationwide were not in compliance with the eight-hour ozone standard and 208 counties nationwide were not in compliance with the $\mathrm{PM}_{2.5}$ standard. As a result, almost 140 million people are living in areas that are in nonattainment with the eight-hour ozone standard and approximately 89 million people are living in a $\mathrm{PM}_{2.5}$ nonattainment area [EPA, 2008b]. On March 27, 2008, EPA announced a new final rule for the NAAQS for ozone that will reduce the standard from $0.08 \mathrm{ppm}$ (widely interpreted as $0.085 \mathrm{ppm}$ since only one significant digit is specified) on an 8 hour average to $0.075 \mathrm{ppm}$ on an 8 hour average, effective on May 27, 2008 [EPA, 2008c]. The rule is expected to lead to an increase in the number of counties designated as non-attainment for ozone, compared to the number so designated under the current rule. There are few to no nonattainment areas at this time for $\mathrm{NO}_{2}, \mathrm{SO}_{2}$, and $\mathrm{CO}$. Thus, the pollutants of greatest interest and concern with respect to current nonattainment areas are $\mathrm{PM}, \mathrm{NO}_{\mathrm{x}}$, and $\mathrm{HC}$. Although $\mathrm{NO}_{\mathrm{x}}$ is emitted primarily as $\mathrm{NO}$, in the atmosphere $\mathrm{NO}$ oxidizes to $\mathrm{NO}_{2}$. $\mathrm{HC}$ is a precursor to $\mathrm{O}_{3}$ and can also be a precursor for some types of particles formed in the atmosphere, as can $\mathrm{NO}_{\mathrm{x}}$. 


\section{OTHER INCENTIVES FOR EMISSION REDUCTIONS}

In addition to the health and environmental incentives for reducing emissions, there are other incentives as well. These incentives include:

- Additional governmental regulations that limit emissions on specific projects

- Proposed regulations that limit carbon dioxide emissions of nonroad vehicles

- New ratings for vehicle fleets that focus on sustainability

- Increased cost savings through reduced fuel use

Many agencies, organizations, and institutions are using specific language in their construction contract specifications to call for vehicle emissions reduction technologies to be implemented on their construction sites. For example, the Connecticut, Massachusetts, and New York Departments of Transportation require that all nonroad diesel vehicles used on their projects employ emissions reduction strategies such as installing engine retrofit technologies, using ultralow sulfur diesel fuel (which enables the use of post-combustion controls for other pollutants), and limiting idling time [Northeast Diesel Collaborative, 2007].

Reducing fuel use in construction vehicles will lower the amount of carbon dioxide $\left(\mathrm{CO}_{2}\right)$ that is emitted into the atmosphere, thus reducing greenhouse gas (GHG) emissions and having a positive impact on climate change. It is likely that $\mathrm{CO}_{2}$ emissions will be regulated in the future. The states of California, Connecticut, Massachusetts, New Jersey, Pennsylvania, and Oregon, have petitioned EPA to monitor GHG emissions for vehicles and equipment in the construction, mining, and agricultural industries. This petition states that EPA should set GHG emissions standards for nonroad vehicles and equipment and then regulate these limits for these machines [EPA Petition, 2008]. Additionally, EPA is planning to provide an Advanced Notice of Proposed Rulemaking (ANPR) to solicit public opinion on this matter [EPA, 2008d]. Note that these are new regulations proposed in addition to the current regulations.

Furthermore, vehicle fleet management is crucial to reducing vehicle emissions. In Canada, the Fraser Basin Council, a nonprofit organization that focuses on sustainability, implemented the E3 Fleet Rating system [Fraser Basin Council, 2006]. This system is comparable to the Leadership in Energy and Environmental Design (LEED) rating system used for buildings by the United States Green Building Council (USGBC) [USGBC, 2006]. The E3 Fleet program rates commercial vehicle fleets based on fleet management practices, energy performance, and emissions performance. This type of program could be and likely will be extended geographically and can include any type of vehicle fleet.

Another incentive for reducing fuel use is cost savings. With current costs exceeding $\$ 4.00$ per gallon, diesel fuel is a significant portion of a vehicle owner's operating expenses. Therefore, there is incentive for the vehicle to operate efficiently and not waste fuel through unnecessary idling and movement. Additionally, reduced idling can lower engine maintenance costs and sustain engine life, which are significant "hidden" cost savings [New York Planning Federation, 2006].

\section{VEHICLES}

The research that supports this paper involved collecting and analyzing in-use emissions and engine data from construction vehicles and equipment as they performed real-world construction 
tasks [Frey et al, 2007a \& b]. The types of construction vehicles selected for data collection were prioritized based on analyses using the United States Environmental Protection Agency's (EPA) NONROAD model [ENVIRON, 2005]. NONROAD was used to rank construction equipment and vehicles based on their respective contribution of nitrogen oxides $\left(\mathrm{NO}_{\mathrm{x}}\right)$, carbon monoxide $(\mathrm{CO})$, and particulate matter $\left(\mathrm{PM}_{10}\right)$. The results are summarized in Table 3 . The selected vehicles and equipment for our data collection study included:

- Backhoes

- Bulldozers

- Excavators

- Front-End Loaders (Rubber-Tire and Track)

- Generators

- Motor Graders

- Off-Highway Trucks

- Skid-Steer Loaders

Items that are mobile are referred to as vehicles and items that are stationary are referred to as equipment. The selected equipment for this study consisted only of generators. For clarification, the rubber-tire loaders, backhoes, motor graders, off-highway trucks, and skid-steer loaders were rubber-tire vehicles and the bulldozers, excavators, and track loaders were track-type vehicles [Rasdorf et al, 2008]. In all we studied 35 vehicles and 4 generators.

These vehicles and equipment are used frequently on construction projects throughout the nation and therefore they contribute significantly to air pollutant emissions. The vehicles and equipment shown in Table 3 are estimated to contribute approximately $85 \%$ of the $\mathrm{NO}_{\mathrm{x}}, \mathrm{CO}$, and $\mathrm{PM}_{10}$ emissions from the approximately two million items of construction vehicles and equipment in the United States. Backhoes, for example, contribute $16.0 \%$ of CO and $15.1 \%$ of $\mathrm{PM}_{10}$ emissions produced by construction vehicles and equipment, which makes them the most significant contributor of these pollutants. However, backhoes are the number five contributor of $\mathrm{NO}_{\mathrm{x}}$ emissions, producing $9.2 \%$.

Motor graders did not rank in the top 10 for any of the three pollutants but they were selected for the study because of their availability for testing and because they are frequently used in road construction and maintenance. Although rough terrain forklifts, scrapers, cranes, and rollers are significant contributors of the three pollutants, they were not selected for this study in order to limit the scope of the project. These vehicles may be targeted for future research.

\section{SOURCES OF EMISSIONS DATA}

Air pollutant emissions data exists in two forms. One form is modeled data and the other form is field data. Modeled data may be derived from engine dynamometer results, results obtained from in-use field data collection, or both. The modeled data examined in this study were obtained from the EPA NONROAD model and the field data were collected from actual construction vehicles using an on-board portable emissions monitoring system (PEMS) while those vehicles were performing construction activities. 
Table 3. Comparison of National Ranking and Contribution of $\mathrm{NO}_{\mathrm{x}}, \mathrm{CO}$, and $\mathrm{PM}_{10}$ for Selected Construction Vehicles and Equipment ${ }^{\text {a }}$

\begin{tabular}{|c|c|c|c|c|c|c|}
\hline \multirow[b]{2}{*}{ Vehicle/Equipment } & \multicolumn{2}{|c|}{ NOx } & \multicolumn{2}{|c|}{$\mathrm{CO}$} & \multicolumn{2}{|c|}{$\mathbf{P M}_{10}$} \\
\hline & $\begin{array}{c}\text { Contribution } \\
(\%)\end{array}$ & $\begin{array}{l}\text { National } \\
\text { Ranking }\end{array}$ & $\begin{array}{c}\text { Contribution } \\
(\%)\end{array}$ & $\begin{array}{l}\text { National } \\
\text { Ranking }\end{array}$ & $\begin{array}{c}\text { Contribution } \\
(\%)\end{array}$ & $\begin{array}{l}\text { National } \\
\text { Ranking }\end{array}$ \\
\hline Front-End Loaders & 14.5 & 1 & 11.5 & 3 & 11.2 & 3 \\
\hline Bulldozers/Track Loaders & 12.5 & 2 & 9.3 & 4 & 9.1 & 4 \\
\hline Excavators & 11.4 & 3 & 7.4 & 5 & 8.6 & 5 \\
\hline Off-Highway Trucks & 11.0 & 4 & 7.3 & 6 & 6.6 & 6 \\
\hline Backhoes & 9.2 & 5 & 16.0 & 1 & 15.1 & 1 \\
\hline Skid-Steer Loaders & 6.2 & 6 & 14.5 & 2 & 13.6 & 2 \\
\hline Generators & 4.7 & 7 & 5.1 & 7 & 6.0 & 7 \\
\hline Rough Terrain Forklifts ${ }^{b}$ & 3.9 & 8 & 4.9 & 8 & 4.6 & 8 \\
\hline Scrapers $^{b}$ & 3.4 & 9 & 2.7 & 11 & 2.3 & 12 \\
\hline Cranes $^{\text {b }}$ & 3.2 & 10 & 1.5 & 15 & 1.9 & 14 \\
\hline Rollers $^{\text {b }}$ & 2.9 & 11 & 2.9 & 10 & 3.0 & 10 \\
\hline \multirow[t]{2}{*}{ Motor Graders } & 2.9 & 12 & 1.7 & 14 & 2.1 & 13 \\
\hline & 85.8 & & 84.8 & & 84.1 & \\
\hline
\end{tabular}

${ }^{a}$ Information in this table is based on equipment data for the year 2000.

${ }^{b}$ These vehicles were not included in the field study due to the limited scope of the project.

The NONROAD model estimates fleet average emissions based on engine data and emission factors. The emission factors are based on steady-state engine dynamometer results that are adjusted by various factors. These factors include the estimated engine load for a type of equipment and duty cycle and the effect of age on emission rates. Furthermore, emissions are estimated based on hours of operation and engine sizes for different types of equipment.

To acquire real-world emissions data requires the measurement of real-world duty cycles of nonroad vehicles that are observed during field data collection. In our study, this was done by connecting a PEMS to the vehicle's engine and to its exhaust system and monitoring the emissions while the vehicle was in use.

The NONROAD emissions estimates and the data collected in the field using the PEMS are not expected to agree exactly because they are collected for different duty cycles. Furthermore, inter-vehicle variability, coupled with a relatively small number of tested vehicles, can lead to random variations in both sets of data. The comparison of NONROAD and PEMS data is based on in-use tests of multiple vehicles of each type as they performed different duty cycles. This paper reports on a set of real-world data collection efforts and compares the field data to the NONROAD model data. 


\section{EPA NONROAD Model}

The EPA NONROAD emissions inventory model is currently the only model approved by EPA for development of SIPs and other regulatory and planning work. Emissions estimates from the model may be provided on a national basis or for specific states and counties. The NONROAD model provides data based on engines rather than on vehicles and equipment because exhaust emissions regulations focus on engines. However, new technologies related to fuels and postcombustion controls are beginning to emerge and are expected to be necessary in order to comply with future regulations. Thus, engine data alone will no longer be representative of the production of emissions.

\section{NONROAD Model Limitations}

The steady state engine dynamometer tests used as the basis for the NONROAD model emission factors do not represent real-world duty cycles. The field use of the vehicles and equipment may impose significantly different loads on the engines than do engine dynamometer tests. Furthermore, the dynamometer tests do not provide insight into the episodic nature of fuel use and emissions during activities that comprise real-world duty cycles, such as idling, use of an attachment, movement of a load, and others. Thus, real-world field duty cycle tests with high temporal resolution are critical. There is a need to quantify emissions and engine information from construction vehicles and equipment based on in-use measurement methods to assess their true level of contribution.

\section{Nonroad Engine Population Estimates}

The NONROAD model provides fleet average emissions estimates according to the following equation [EPA, 2004b]:

Emissions $=$ Pop $x$ Power $x$ LF $x A \times E F$

where:

Pop = Engine Population

Power $=$ Average Engine Power $(\mathrm{hp})$

$\mathrm{LF} \quad=$ Load Factor (fraction of available engine power)

A = Activity (hrs/yr)

$\mathrm{EF} \quad=$ Emission Factor $(\mathrm{g} / \mathrm{hp}-\mathrm{hr})$

The engine populations provided by the NONROAD model are for a given base year and are categorized by application, fuel type, and power level. The base year for the vehicles in this study was 2000 because that was the most recent year for which data was available. The application for the selected vehicles was construction and the fuel type was diesel.

Since the emission factor is estimated in units of grams per horsepower-hour (g/hp-hr), engine activity in units of hours of operation must be known. Also, the engine load, or fraction of available power, must be known. This information may not be known by vehicle or fleet owners. Therefore, the NONROAD model provides default input values for annual activity and load factors for various types of nonroad engines [EPA, 2004b].

The NONROAD model classifies engines into 18 power level categories to account for emission regulations and technology differences. To simplify calculating an emissions inventory, an 
average horsepower based on a sales-weighted average is specified for each power level. Although stratifying the engine population data by application, fuel type, and power level helps to make detailed distinctions, it may also result in small engine populations for some applications and power levels [EPA, 2004c]. Also, such data are difficult to obtain and may be based on proprietary databases.

\section{Exhaust Emissions Estimates}

Emissions inventories are useful for trend analysis, regulatory impact analysis, human exposure modeling, and air quality modeling [NARSTO, 2006]. The NONROAD model estimates the number of tons per year of emissions for $\mathrm{HC}, \mathrm{CO}, \mathrm{NO}_{\mathrm{x}}, \mathrm{CO}_{2}, \mathrm{SO}_{2}$, and $\mathrm{PM}$ for each vehicle type and each power level category.

To illustrate the type of emissions information that can be estimated by using the NONROAD model, Table 4 summarizes exhaust emissions estimates for the population of backhoes in the United States for each power level category. Note that there are fewer power levels shown in Table 4 than are defined in the NONROAD model. This is because the population of backhoes only used engines of the levels specified in Table 4. The average engine horsepower, number of backhoes, and number of emitted tons per year for each of the listed pollutants in each power level category are shown.

\section{Field Data Collection}

One of the goals of this work was to measure air pollutant emissions data in the field from in-use construction vehicles because the availability of this type of data was limited. This section describes the instrumentation that was used to collect this data as well as the environment in which the data was collected. Additionally, the vehicle activity modes that were monitored during field data collection are described.

\section{Field Data Collection Limitations}

Collection of emissions data from construction vehicles and equipment based on in-use measurement methods was needed because there was limited real-world data in this area that represented construction activities. Previous studies had been conducted by the EPA, West Virginia University, Clean Air Technologies International, Inc (CATI), and University of California at Riverside to obtain in-use measurements of emissions data on construction vehicles [May et al, 2002; Gautam et al., 2002; Vojtisek-Lom, 2003; University of California-Riverside, 2007]. Portions of this data have not been quality assured, or are not available to the public, other than in summary form. Furthermore, a relationship was not established between the vehicle activity patterns, fuel consumption, and emissions. The results of this work address vehicle activity, fuel use, and emissions and provide a base methodology for, and prioritization of, additional real-world emissions data measurement. 
Table 4. Summary of 2000 Emissions Estimates for Backhoes in United States Based on the EPA NONROAD Model

\begin{tabular}{|c|c|c|c|c|c|c|c|c|}
\hline $\begin{array}{c}(1) \\
\text { Power } \\
\text { Level } \\
(\text { hp) }\end{array}$ & $\begin{array}{c}(2) \\
\text { Average } \\
\text { Power } \\
\text { (hp) }\end{array}$ & $\begin{array}{c}\text { (3) } \\
\text { Population } \\
\text { (each) }\end{array}$ & $\begin{array}{c}\mathbf{4}) \\
\mathrm{HC} \\
\text { (tons/yr) }\end{array}$ & $\begin{array}{c}\mathbf{5}) \\
\mathbf{C O} \\
\text { (tons/yr) }\end{array}$ & $\begin{array}{c}(6) \\
\text { NO } \\
\text { (tons/yr) }\end{array}$ & $\begin{array}{c}\mathbf{( 7 )} \\
\mathrm{CO}_{2} \\
\text { (tons/yr) }\end{array}$ & $\begin{array}{c}(8) \\
\mathbf{S O}_{2} \\
\text { (tons/yr) }\end{array}$ & $\begin{array}{c}\text { (9) } \\
\text { PM } \\
\text { (tons/yr) }\end{array}$ \\
\hline 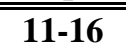 & ב 16 & $\overline{\overline{6}}$ & " & " & " & 16 & 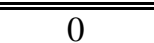 & 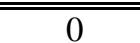 \\
\hline $16-25$ & 22 & 2,615 & 42 & 166 & 117 & 10,757 & 15 & 24 \\
\hline $25-40$ & 33 & 5,226 & 105 & 403 & 287 & 30,713 & 43 & 62 \\
\hline $40-50$ & 46 & 2,792 & 80 & 307 & 218 & 23,347 & 33 & 47 \\
\hline $50-75$ & 63 & 52,153 & 1,614 & 7,328 & 6,541 & 590,520 & 826 & 1,262 \\
\hline $75-100$ & 87 & 184,254 & 7,960 & 36,132 & 32,253 & $2,911,663$ & 4,075 & 6,220 \\
\hline $100-175$ & 121 & 122,598 & 5,298 & 22,251 & 31,700 & $2,419,014$ & 3,386 & 3,627 \\
\hline $175-300$ & 200 & 668 & 45 & 186 & 279 & 21,835 & 31 & 31 \\
\hline
\end{tabular}

\section{Field Data Collection Instrumentation}

The emissions data for each vehicle were collected using a PEMS. The PEMS used in this study was the Montana system manufactured by CATI, Inc. [Rasdorf et al, 2008]. The Montana system measures second-by-second mass emissions. For vehicles with diesel engines, the Montana system collects emissions data for the following pollutants:

- Nitric Oxide (NO)

- Carbon Monoxide (CO)

- Carbon Dioxide $\left(\mathrm{CO}_{2}\right)$

- Hydrocarbons (HC)

- Particulate Matter (PM)

The Montana system is installed on the construction vehicle and connected to the vehicle's engine. The Montana system gathers air pollutant emissions data using a sample probe inserted into the tailpipe while the vehicle performs real-world construction activities. The Montana system also collects engine information such as manifold absolute pressure (MAP), intake air temperature (IAT), and revolutions per minute (RPM) using sensors temporarily installed on the engine. The air pollutant emissions data and the engine data are used to estimate emission rates.

\section{Field Data Collection Environment}

Construction site activities can vary greatly, ranging from controlled to chaotic. Controlled activities consistently follow specific procedures that are usually easy to quantify, such as an excavator loading soil from a borrow pit into dump trucks. Chaotic activities have no predetermined procedures and may be difficult to quantify, such as a skid-steer loader moving about randomly to remove debris from a construction site. In general, controlled activities are considered to be more desirable for modeling. However, chaotic activities must be monitored as well if all activities are to be correctly modeled.

The construction environment can be challenging, highly variable, and subject to change due to weather, site conditions, job requirements, and coordination with other activities. Therefore, there is high variability in real-world construction activities, especially relative to productivity 
and quality. This variability leads to significant data collection challenges. One of these is simply describing and measuring what a vehicle is doing at a given point in time.

This variability emphasizes the need to collect emissions data from vehicles and equipment that are performing real-world activities because those activities may consist of significantly different tasks that are performed under significantly different conditions. More thorough emissions estimates of vehicles and equipment can be determined by measuring real-world emissions data for all types of vehicle activity, ranging from the controlled to the chaotic.

\section{Vehicle Activity Modes}

To address an item causing variability and to establish a link between emissions and vehicle activity, the emissions field data that were collected as part of this work were categorized by activity modes that the vehicle performed. These activity modes varied with each type of construction vehicle.

Activity modes are those activities which were anticipated, prior to data collection, to produce a significant or discernable amount of air pollutant emissions, such as idling, moving, or using an attachment (i.e. front bucket, excavator bucket, or a blade). These activity modes are simplifications of more complex construction activities. For example, a bulldozer may produce detectable but varying levels of emissions while it is idling, while it is moving either in a forward or reverse direction without using its blade, or while it is pushing or spreading material with its blade. These activity modes are observable and recordable for data collection purposes.

Table 5. Vehicle Activity Modes for Construction Vehicles

\begin{tabular}{|c|c|}
\hline Vehicle & Activity Mode \\
\hline Backhoe & $\begin{array}{c}\text { Idling } \\
\text { Moving } \\
\text { Bucket } \\
\text { Scoop/Dump } \\
\end{array}$ \\
\hline Bulldozer & $\begin{array}{c}\text { Idling } \\
\text { Forward } \\
\text { Reverse } \\
\text { Blade } \\
\end{array}$ \\
\hline Excavator & $\begin{array}{c}\text { Idling } \\
\text { Moving } \\
\text { Scoop/Dump } \\
\text { Cycle }\end{array}$ \\
\hline Front-End Loader & $\begin{array}{c}\text { Idling } \\
\text { Moving } \\
\text { Scoop/Dump } \\
\end{array}$ \\
\hline Generator & $\begin{array}{c}\text { Idling } \\
\text { Non-Idling }\end{array}$ \\
\hline Motor Grader & $\begin{array}{c}\text { Idling } \\
\text { Moving } \\
\text { Blade }\end{array}$ \\
\hline Off-Road Truck & $\begin{array}{c}\text { Idling } \\
\text { Moving } \\
\text { Hauling } \\
\text { Dumping }\end{array}$ \\
\hline Skid-Steer Loader & $\begin{array}{c}\text { Idling } \\
\text { Moving }\end{array}$ \\
\hline
\end{tabular}


Table 5 shows all of the types of vehicles that were tested and the corresponding activity modes for each vehicle. In total, 35 vehicles and 4 generators from these eight categories have been tested to date.

A laptop computer was used by a research assistant to enter time stamps and labels for activity modes for each construction vehicle. The time stamps were recorded by an Excel macro based on user input via a numeric keypad. For example, the activity modes and their corresponding number for a bulldozer were:

1. Idling

2. Forward

3. Reverse

4. Blade

Since the time was recorded for each keystroke, the duration of each recorded activity mode could be determined. Furthermore, the clock of the laptop computer was synchronized with the clock of the Montana system to enable a second-by-second analysis of the emissions for each activity mode. Thus, it was possible to determine the emissions per unit of time for each activity mode, i.e. milligrams per second (mg/s) [Rasdorf et al, 2008].

Figure 1 depicts one link between emissions and activity modes based on field data collection. This type of graph was produced for each vehicle that was tested. Figure 1 shows that Bulldozer 4 emitted NO at its lowest rate while idling and at its highest rate while using the blade. This is because the bulldozer is subjected to a higher engine load while exerting force to move material with the blade and a lower engine load while idling and not moving or performing work with the blade. There was little difference in the average emission rates for the bulldozer moving in a forward or a reverse direction because the required engine load was necessary to only move the bulldozer itself and not any additional material with the blade.

\section{COMPARISONS OF EMISSIONS DATA}

Comparisons between the PEMS data and the NONROAD model data were made to determine if the two sources were of similar relationship. Our expectation was that the two sources of data were not likely to agree closely because the PEMS data were for individual vehicles, whereas the NONROAD model data was intended to predict average emissions for a fleet of vehicles. Also, the real-world duty cycles and ambient conditions of the PEMS data differed from the standardized engine dynamometer test conditions used by the NONROAD model.

In order to make a direct comparison, the emission factors based on the NONROAD model were converted to a fuel basis using a default brake-specific fuel consumption (BSFC) estimate. The NONROAD model calculates the exhaust emission factors for $\mathrm{HC}, \mathrm{CO}$, and $\mathrm{NO}_{\mathrm{x}}$ for a given type of diesel vehicle with a given model year, engine size, and hours of engine operation based on the following equation [EPA, 2004a]:

$E F_{\text {adj }(H C, C O, N O x)}=E F_{s s} \times T A F \times D F$

where:

$\mathrm{EF}_{\mathrm{adj}}=$ Emission Factor used, including the adjustments for transient operation and deterioration $(g / h p-h r)$ 
$\mathrm{EF}_{\mathrm{ss}} \quad=$ Zero-hour, steady-state emission factor $(g / h p-h r)$

TAF $=$ Transient Adjustment Factor (unitless)

$\mathrm{DF} \quad=$ Deterioration Factor (unitless)

The transient adjustment factor represents the variation in vehicle type and the fraction of engine power that is used. The deterioration factor is a function of engine age based on the accumulation of operating hours.

The level of PM emissions is dependent upon the sulfur content of the fuel that is being used in the engine. Therefore, Equation (2) is modified slightly to calculate the exhaust emission factor PM [EPA, 2004a].

$E F_{a d j .(P M)}=E F_{s s} \times T A F \times D F-S_{P M a d j}$

where:

$\mathrm{S}_{\mathrm{PMadj}}=$ Adjustment to $\mathrm{PM}$ emission factor to account for variations in the sulfur content of the fuel $(g / h p-h r)$

In real-world measurements, emission factors are obtained in units of grams per second $(\mathrm{g} / \mathrm{s})$ or grams per gallon of fuel consumed (g/gal) [Vojtisek-Lom, 2003]. To enable comparisons with the PEMS data, the emission factors in the NONROAD model were converted to units of grams per gallon of fuel (g/gal) using an assumed brake-specific fuel consumption rate (BSFC) in units of pounds of fuel used per horsepower-hours (g/hp-hr) [EPA, 2004a].

EPA assumes a constant BSFC for each engine tier within a specified engine horsepower range, without regard for the duty cycle being performed by the vehicle. However, during field data collection it was observed that fuel consumption rates vary among individual vehicles. This difference is due to the duty cycle of the vehicle. Although assuming a constant fuel consumption rate for all engine tiers may make it easier to calculate emission rates, this assumption may not be representative of real-world conditions.

The corrected emission factors are calculated in units of grams per gallon as follows:

$$
E F_{\text {corr }}\left(\frac{g}{g a l}\right)=E F_{a d j}\left(\frac{g}{h p-h r}\right) \times \frac{1}{B S F C}\left(\frac{h p-h r}{l b}\right) \times C F\left(\frac{l b}{g a l}\right)
$$

where:

$\mathrm{EF}_{\text {corr }}=$ Corrected Emission Factor $(\mathrm{g} / \mathrm{gal})$

$\mathrm{EF}_{\mathrm{adj}}=$ Emission Factor $(g / h p-h r)$

$\mathrm{BSFC}=$ Brake-Specific Fuel Consumption rate $(l b / h p-h r)$

$\mathrm{CF} \quad=$ Conversion Factor $(\mathrm{lb} / \mathrm{gal})$

The ranges of the emission rates for all vehicles based on the field data were compared with similar estimates from the NONROAD model. Samples of these comparisons for three types of vehicles are summarized in Table 6. The ranges of data shown in Table 6 are influenced by different engine tiers because vehicles with lower tier engines have higher emission rates than vehicles with higher tier engines. 
In general, the average emission rates from the PEMS field measurement data are of similar magnitude to those based on the NONROAD model for NO, HC, and CO. For example, based on the NONROAD model, the average emission rate for $\mathrm{NO}_{\mathrm{x}}$ as equivalent $\mathrm{NO}_{2}$ for a motor grader varies from approximately 45 to $159 \mathrm{~g} / \mathrm{gallon}$. According to the PEMS data, the average emissions rate of $\mathrm{NO}$ as equivalent $\mathrm{NO}_{2}$ is approximately 59 to $139 \mathrm{~g} / \mathrm{gallon}$.

However, the magnitude and range of the PEMS emission rates for PM is much smaller in comparison to the NONROAD ranges of emission rates for PM. This is due to the fact that PM data is collected by the PEMS by a laser light scatter method, rather than by a filter-based method. A systematic measurement bias for the PM concentration has been reported for this type of instrument [CATI, 2007]. However, even though there may be bias in the absolute value of the PM emission factor data, the results can still be used to make relative comparisons and evaluate trends in PM emission rates for different types of vehicles.

Table 6. Comparison of Ranges of Emission Factors from Two Data Sources for Three Types of Construction Vehicles [Frey et al, 2007a]

\begin{tabular}{|c|c|c|c|c|c|c|c|c|c|c|}
\hline \multirow[b]{2}{*}{ Vehicle } & \multirow[b]{2}{*}{ Vehicle ID } & \multirow[b]{2}{*}{ Tier } & \multicolumn{2}{|c|}{$\begin{array}{c}\mathrm{NO}_{\mathrm{x}} \\
\text { (g/gal) }\end{array}$} & \multicolumn{2}{|c|}{$\begin{array}{c}\mathbf{H C} \\
\text { (g/gal) }\end{array}$} & \multicolumn{2}{|c|}{$\begin{array}{c}\mathbf{C O} \\
\text { (g/gal) }\end{array}$} & \multicolumn{2}{|c|}{$\begin{array}{c}\text { PM } \\
\text { (g/gal) }\end{array}$} \\
\hline & & & $\overline{\text { EPA }^{a}}$ & PEMS $^{\mathbf{b}}$ & $\overline{\text { EPA }^{\mathbf{a}}}$ & PEMS $^{\mathbf{b}}$ & $\overline{\text { EPA }^{\mathbf{a}}}$ & PEMS $^{\mathbf{6}}$ & $\overline{\text { EPA }^{\mathbf{a}}}$ & PEMS $^{\mathbf{b}}$ \\
\hline \multirow{5}{*}{ Backhoe } & $\begin{array}{l}\text { BH } 2 \\
\end{array}$ & " & " & $798-115$ & "34 & "13-17 & " 144 & "82-106 & 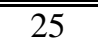 & $1.1-1.3$ \\
\hline & BH 4 & 1 & 91 & $93-120$ & 18 & $5.6-9.1$ & 93 & $45-54$ & 15 & $1.3-1.7$ \\
\hline & BH 3 & 1 & 90 & $99-103$ & 18 & $11-15$ & 92 & $36-39$ & 14 & $0.9-1.2$ \\
\hline & BH 5 & 2 & 75 & $96-110$ & 12 & $8.6-10$ & 90 & $16-17$ & 6.2 & $0.7-0.8$ \\
\hline & BH 1 & 2 & 75 & $92-105$ & 12 & $10-12$ & 90 & $8.4-9.3$ & 6.2 & $0.66-0.7$ \\
\hline \multirow{4}{*}{$\begin{array}{l}\text { Front- } \\
\text { End } \\
\text { Loader }\end{array}$} & FL 3 & 1 & 104 & $125-129$ & 7.0 & 13 & 28 & $12-14$ & 8.4 & $0.89-0.94$ \\
\hline & FL 1 & 1 & 103 & $108-113$ & 6.9 & $\begin{array}{l}17-19 \\
\end{array}$ & 27 & $15-18$ & 6.9 & 1.0 \\
\hline & FL 2 & 1 & 103 & $127-131$ & 6.9 & $16-17$ & 27 & $12-14$ & 6.9 & $0.49-0.51$ \\
\hline & Fl 4 & 2 & 74 & $94-96$ & 6.8 & $5.4-5.8$ & 26 & 11 & 3.4 & $0.62-0.66$ \\
\hline \multirow{6}{*}{$\begin{array}{l}\text { Motor } \\
\text { Grader }\end{array}$} & MG 4 & 0 & 159 & $126-134$ & 15 & $16-21$ & 110 & $27-34$ & 18 & $0.77-0.93$ \\
\hline & MG 5 & 0 & 157 & $136-139$ & 15 & $12-17$ & 105 & $26-46$ & 16 & $1.0-1.1$ \\
\hline & MG 1 & 1 & 102 & $104-113$ & 6.3 & $13-17$ & 23 & $12-15$ & 6.8 & $0.86-0.90$ \\
\hline & MG 3 & 1 & 102 & $105-115$ & 6.3 & $17-19$ & 23 & $15-16$ & 6.8 & 0.80 \\
\hline & MG 2 & 2 & 75 & $90-106$ & 6.2 & $9.2-15$ & 23 & $8.5-15$ & 2.9 & $0.62-0.65$ \\
\hline & MG 6 & 3 & 45 & $59-77$ & 3.7 & $4.5-7.9$ & 22 & $8.7-9.3$ & 1.8 & $0.53-0.61$ \\
\hline
\end{tabular}

a: Emission Factors calculated from EPA's NONROAD model data

${ }^{\mathrm{b}}$ : Emission Factors determined from PEMS field measurement data

Although the PEMS results appear to be in concordance with the NONROAD model results, there are many advantages of the PEMS results:

- The PEMS results are based on actual data from in-use vehicles performing real-world duty cycles as opposed to the use of transient adjustment factors in NONROAD that approximate usage.

- The PEMS results are based on actual engine loads as opposed to the NONROAD model engine load factors that estimate a fraction of the engine power that is used.

- The PEMS data can be used to characterize the episodic variation in fuel use and emission rates attributable to specific activities within a duty cycle, which is not possible with the dynamometer data used as the basis for the NONROAD model. 
- The PEMS results are based on actual fuel consumption rates. Actual fuel consumption rates are more realistic than the EPA assumed brake-specific fuel consumption rate. It is often possible to determine actual fuel consumption rates from vehicle fleet records because many fleet owners track annual fuel use as an expense.

- Fuel-based emission factors based on actual fuel consumption rates from the PEMS are more reliable than time and load based (hp-hr) emission factors for estimating emissions inventories. This is because most vehicle owners have accurate records of fuel consumption but they likely do not have accurate records of vehicle activity time and engine load. Furthermore, there is less variability in emissions estimates when using fuel-based emission factors.

- Real-world data may be used to verify and evaluate the effectiveness of emissions reduction strategies, such as alternative fuels, fuel additives, new engine technologies, future post-combustion controls, and operational practice. For example, significant reductions of $\mathrm{CO}, \mathrm{HC}$, and $\mathrm{PM}$ were found when using $\mathrm{B} 20$ biodiesel in lieu of petroleum diesel in construction vehicles. Furthermore, significant reductions for these pollutants were also found when comparing a Tier 3 engine to those of earlier tiers [Frey et al, 2008].

\section{CONCLUSIONS AND RECOMMENDATIONS}

There is growing recognition of the need to quantify and manage emissions from construction vehicles. However, the available data based on the NONROAD emissions model provide only average emission factors. In contrast, real world data from PEMS can be used to quantify real world duty cycles and the influence of episodic events on fuel use and emissions rates.

Increasingly stringent emission standards will be implemented for which it is desirable to have a methodology for assessing their effectiveness in the real world. Furthermore, there will be additional incentives to reduce emissions, such as via project bid requirements and possible green fleet certification programs. Assessment of the effectiveness of attempts to respond to such incentives depends on real world data. There are key types of construction vehicles and equipment that contribute the most to estimated national emissions; therefore, there is a basis for initially prioritizing efforts to collect real world data. Fuel-based emission factors are typically found to be less subject to variations among duty cycles than time-based emission factors.

The construction industry must raise its level of awareness of the environmental impacts of construction, particularly with respect to air pollutant emissions of nonroad diesel construction vehicles. In particular, there are a number of specific activities that could be undertaken by the industry including those recommended here:

1. Establish an accurate real-world baseline assessment of current emissions based on realworld data.

2. Contribute to finding ways to reduce the air pollutant emissions of construction vehicles to improve air quality.

3. Determine the effects on emissions of alternative fuels, such as biodiesel, when used in construction vehicles.

4. Use real-world data to verify and evaluate vehicle emissions under actual operating conditions. This evaluation may be used to assess the benefits of replacing older vehicles 
with newer ones or to assess rebuilding or replacing older engines without replacing the vehicle itself.

5. Modify construction vehicle operation procedures, such as reducing idling time to decrease fuel used and therefore reduce air pollutant emissions. This can be accomplished by turning off the vehicle when it is not in use, carefully planning travel routes, etc.

6. Improve vehicle maintenance procedures.

7. Procure energy efficient equipment and vehicles.

8. Investigate technological controls for construction vehicles that will reduce air pollutant emissions, such as selective catalytic reduction, diesel oxidation catalysts, diesel particulate filters, closed crankcase ventilation systems, and exhaust gas recirculation.

9. Develop green fleet certification programs that take into account measured real world factors that prevent or reduce emissions, and that encourage verification of the effectiveness of such programs in reducing emissions based on real world data.

10. Develop air pollutant emissions inventories based on accurate emission factors for construction vehicles.

11. Use the air pollutant emission inventories to develop air pollutant emissions projections for new projects. These projections would be based on typical construction planning metrics such as plans, specifications, contract documents, estimates, and work to be performed.

Of course, these activities should be conducted in collaboration with university researchers, with manufacturers, and with owners of large vehicle and equipment fleets such as state departments of transportation and equipment rental companies. University environmental and construction faculty can contribute to the quantification of the effects of alternative fuels, technologies, and operational practice on energy use and emissions.

In addition to research, faculty should incorporate the environmental impacts of construction into civil, construction, and environmental engineering curricula. These environmental impacts include, but are not limited to air quality, water runoff, waste management, and hazardous site remediation. Air quality, for example, could be incorporated into the typical undergraduate construction equipment class and could be studied in more detail in a graduate equipment class. Doing so would lend itself particularly well to simulation studies.

\section{FUTURE WORK}

Much remains to be done to establish the foundation on which to implement the recommendations just noted. This paper seeks to call this important area to the attention of construction researchers, educators, and decision-makers who have the resources to commit to these efforts. Additional research is needed to collect and analyze additional air pollutant emissions data for the construction vehicles mentioned in this paper and for other construction vehicles as well. Simply not enough is known about in-use emissions performance. Without such data, mitigation procedures cannot be initiated as effectively as desired.

Using the aforementioned data, emission factors can be determined and used to assess air pollutant emissions for construction vehicle tasks, such as excavation. This comparison can be used to link the grams of pollutant to the common quantity of work performed, such as cubic yards of excavation. The resulting emission factor of grams of pollutant emitted per cubic yard 
of excavation can enable estimates of future construction emissions to be made. Also, emissions could be linked to a typical excavation operation on a micro-scale, consisting for example, of an excavator working with one or more dump trucks in a typical earthmoving operation. Especially in non-attainment areas, results from studies such as these can be used as important components of environmental impact analyses.

However, it will be necessary to have accurate emissions data and accurate operational data for these emission factors to be meaningful. Controlled field testing may be required to obtain them. The PEMS data reported here were collected in an uncontrolled observational mode. Finally, based on the results of the controlled field testing, new emission factors can be developed for each construction vehicle.

\section{ACKNOWLEDGEMENTS}

This material is based upon work supported by the National Science Foundation through Grant No. 0327731 and also by the North Carolina Department of Transportation through Research Project No. HWY - 2006 - 08. Any opinions, findings, and conclusions or recommendations expressed in this material are those of the authors and do not necessarily reflect the views of the NSF or the NCDOT.

\section{REFERENCES}

CFR (2007). "Title 40 - Protection of Environment, Part 50 - National Primary and Secondary Ambient Air Quality Standards," Federal Register.

Cooper, C. David and Alley, F.C. (2002). Air Pollution Control: A Design Approach. Waveland Press, Long Grove, Illinois.

Environ (2005). NONROAD2005 MODEL, EPA-420-R-05-013, Prepared by Environ for Office of Transportation and Air Quality, U.S. Environmental Protection Agency, Ann Arbor, MI, December.

EPA (2004a). "Exhaust and Crankcase Emission Factors for Nonroad Engine Modeling Compression-Ignition," EPA420-P-04-009, NR-009c, U.S. Environmental Protection Agency, Washington, D.C.

EPA (2004b). "Median Life, Annual Activity, and Load Factor Values for Nonroad Engine Emissions Modeling," EPA420-P-04-005, NR-005c, U.S. Environmental Protection Agency, Washington, D.C.

EPA (2004c). "Nonroad Engine Population Estimates," EPA420-P-04-006, NR-006c, U.S. Environmental Protection Agency, Washington, D.C.

EPA (2005a). “Clean Construction USA,” EPA-420-F-05-032, U.S. Environmental Protection Agency, Washington, D.C.

EPA (2005b). "Clean Air Nonroad Diesel Rule Summary," EPA-420-F-04-029, U.S. Environmental Protection Agency, Washington, D.C.

EPA (2005c). "National Clean Diesel Campaign Fact Sheet," EPA-420-F-05-012, U.S. Environmental Protection Agency, Washington, D.C. 
EPA (2007a). "National Clean Diesel Campaign," www.epa.gov/cleandiesel, Information viewed on September 19, 2007.

EPA (2007b). "Nonroad Diesel Equipment," www.epa.gov/otaq/regs/nonroad/equip-hd, Information viewed on September 19, 2007.

EPA (2008a). "Latest Findings on National Air Quality," EPA454/R-07-007, U.S. Environmental Protection Agency, Washington, D.C.

EPA (2008b). "The Green Book Nonattainment Areas for Criteria Pollutants," www.epa.gov/oar/oaqps/greenbk, Information viewed on April 3, 2008.

EPA (2008c), "40 CFR Parts 50 and 58, National Ambient Air Quality Standards for Ozone; Final Rule," Federal Register, 73(60):16435-16514.

EPA (2008d). Correspondence from Stephen L. Johnson, U.S. Environmental Protection Agency, to Henry A. Waxman and Tom Davis, U.S. House of Representatives, March 27, 2008, Washington, D.C. (http://oversight.house.gov/documents/20080327170233.pdf).

EPA Petition (2008). "Petition for Rulemaking Seeking the Regulation of Greenhouse Gas Emissions from Nonroad Vehicles and Engines," Submitted by the States of California, Connecticut, Massachusetts, New Jersey, Oregon, and Pennsylvania to the Environmental Protection Agency, January 29, (http://ag.ca.gov/cms attachments/press/pdfs/n1522 finaldraftnonroadpetition3.pdf).

Fraser Basin Council (2006). "E3 Fleet Rating System Handbook," Vancouver, B.C.

Frey, C., Rasdorf, W., Kim, K., Pang, S., Lewis, P., Abolhassani, S. (2007a). "Real-World Duty Cycles and Utilization for Construction Equipment in North Carolina," FHWA/NC/ 2006 55, Prepared by North Carolina State University for North Carolina Department of Transportation, Raleigh, NC.

Frey, C., Rasdorf, W., Kim, K., Pang, S.-H., Lewis, P., and Abolhassani, S. (2007b). "Life Cycle Inventory and Impact Analysis Framework for Nonroad Construction Vehicles and Equipment Based Upon In-Use Measurements," Technical Report, Prepared by North Carolina State University for National Science Foundation, Washington, D.C.

Frey, H. C., Rasdorf, W., Kim, K., Pang, S-H., and Lewis, P. (2008). "Comparison of Real World Emissions of Backhoes, Front-End Loaders, and Motor Graders for B20 Biodiesel vs. Petroleum Diesel and for Selected Engine Tiers," Transportation Research Record, (In Press).

Gautam, M.; Carder, D.; Clark, N.; Lyons, D. W. (2002). "Testing for Exhaust Emissions of Diesel Powered Off-Road Engines," APB contract number 98-317, Prepared by West Virginia University for the California Air Resources Board and the California EPA, Sacramento, CA.

May, D. F., Fisher, L., Tennis, C., Parrish, T. (2002). "Simple, Portable, On-vehicle Testing (SPOT) Final Report," Contract number 86-C-01-106, Prepared by Analytical Engineering, Inc. for the U.S. Environmental Protection Agency, Columbus, IN.

NARSTO (2006). Improving Emission Inventories for Effective Air Quality Management Across North America, A NARSTO Assessment, NARSTO-05-001, Prepared by NARSTO, August, 2005. available at: http://www.narsto.org/section.src?SID=8, 2005. 
New York Planning Federation (2006). “A Municipal Official's Guide to Diesel Idling Reduction in New York State," Technical Report with funding from New York State Energy Research and Development Authority and U.S. Environmental Protection Agency's Smartway Transport Partnership.

Northeast Diesel Collaborative (2007). "Construction," www.northeastdiesel.org/construction, Information viewed on December 13, 2007.

Rasdorf, W., Frey, C., Lewis, P., Kim, K., Pang, S., Abolhassani, S. (2008). "Field Procedures for Measuring Air Pollutant Emissions of Nonroad Diesel Engine Construction Vehicles," Journal of Construction Engineering and Management, Submitted October 2007.

Seinfeld, J.H., and Pandis, S.N. (1998). Atmospheric Chemistry and Physics: From Air Pollution to Climate Change. Wiley-Interscience, Hoboken, New Jersey.

Tietenberg, T. (2007). Environmental Economics and Policy, Fifth Edition, Pearson Education, Inc., Boston, Massachusetts.

University of California - Riverside (2007). "Evaluating the Emissions from Heavy-Duty Diesel Construction Equipment," In proceedings of the $17^{\text {th }}$ CRC On-road Vehicle Emissions Workshop, San Diego, CA, Coordinating Research Council: Atlanta, GA.

USGBC (2006). "Foundations of the Leadership in Energy and Environmental Design Environmental Rating System A Tool for Market Transition," U.S. Green Building Council, Washington, D.C.

Vojtisek-Lom, M. (2003). "Real-World Exhaust Emissions from Construction Equipment at the World Trade Center \#7 Site," Prepared by Clean Air Technologies International, Inc. for Northeast States for Coordinated Air Use Management, Buffalo, NY.

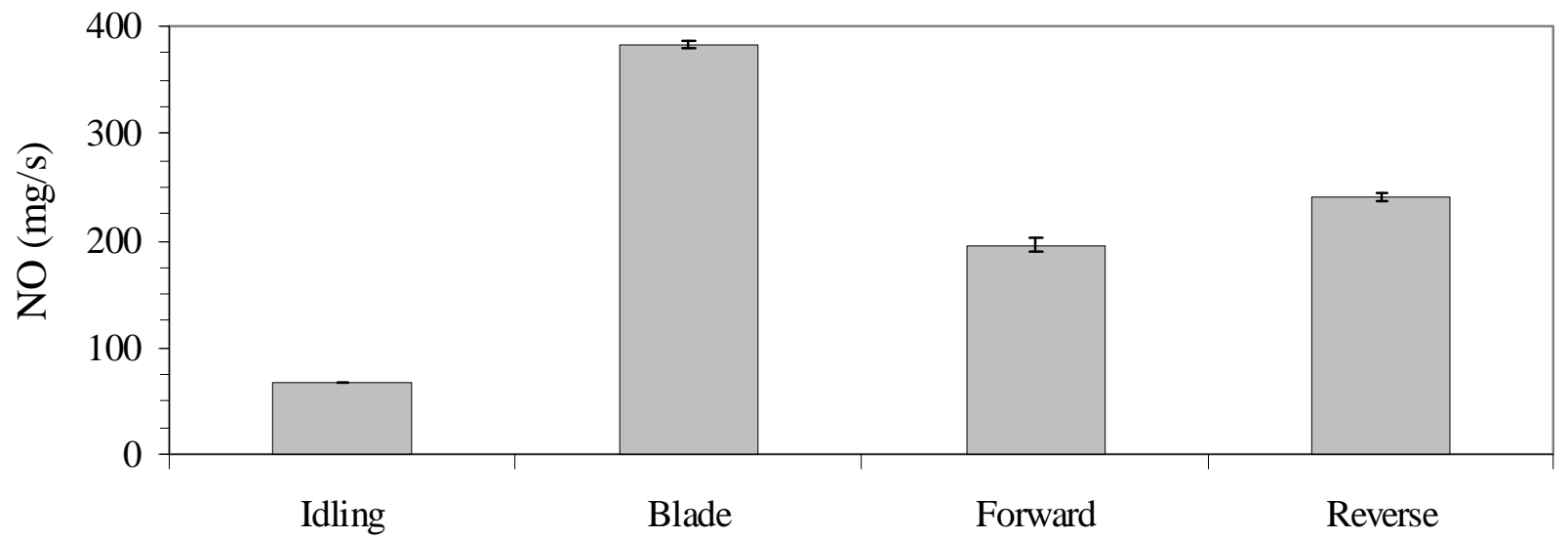

Figure 1. Average Emission Rates of NO on a Per Time Basis by Activity Mode for Bulldozer 4 Tested on September 28, 2007 